\title{
Transposition
}

Musique et Sciences Sociales

$8 \mid 2019$

Musique : patrimoine immatériel ?

\section{Aimée Boutin, City of Noise: Sound and Nineteenth- Century Paris}

Urbana, University of Illinois Press, 2015

\section{Samuel Llano}

\section{OpenEdition}

\section{Journals}

Electronic version

URL: http://journals.openedition.org/transposition/3401

DOI: 10.4000/transposition.3401

ISSN: 2110-6134

Publisher

CRAL - Centre de recherche sur les arts et le langage

\section{Electronic reference}

Samuel Llano, « Aimée Boutin, City of Noise: Sound and Nineteenth-Century Paris », Transposition [Online] 8 | 2019, Online since 15 September 2019, connection on 16 December 2020. URL : http://

journals.openedition.org/transposition/3401 ; DOI : https://doi.org/10.4000/transposition.3401

This text was automatically generated on 16 December 2020 .

La revue Transposition est mise à disposition selon les termes de la Licence Creative Commons Attribution - Partage dans les Mêmes Conditions 4.0 International. 


\title{
Aimée Boutin, City of Noise: Sound and Nineteenth-Century Paris
}

Urbana, University of Illinois Press, 2015

\author{
Samuel Llano
}

\section{REFERENCES}

Aimée Boutin, City of Noise: Sound and Nineteenth-Century Paris, Urbana, University of Illinois Press, 2015, 208 p.

1 City of Noise is doubtlessly a groundbreaking contribution to the study of historical urban soundscapes in modern cities. The book takes significant steps towards understanding the complex relationship between, on one hand, the different sound practices that take place in the city, and, on the other, the economic and cultural struggles in which different urban population groups took part. Boutin thus makes a valuable contribution towards understanding the ways in which sound practice and attitudes towards noise are involved in the production of space, the construction of identities, and the negotiation of class structures in the nineteenth-century city. In so doing, this study joins the ranks of John Picker, Karin Bijsterveld, David Hendy, and Ian Biddle and Kirsten Gibson ${ }^{1}$. It is, however, rather unique in that it draws mainly, though not only, on literary studies.

2 City of Noise will surely inspire future work on historical urban soundscapes, but readers should not expect to find in it a universal model that can be applied to any city, time or geography. The book does neither aim to do so, nor try to address the question "how did Paris sound like?" Instead, City of Noise analyses the ways in which sound and noise contributed to the rise of self-awareness among urban dwellers, and shaped modern subjectivities at a time of deep urban transformation under Hausmann's plan. "Noise perception is subjective" (p.3) - Boutin claims - and it changes over time. Literary sources, poems, guidebooks and visual sketches give us access to qualitative aspects of sound perception, and to the "cultural significance ascribed to the networks of sonic 
relations" deployed in the city. In so doing, City of Noise delves deep into the heart of one of the most problematic questions inherent in the study of sound cultures dating from before the advent of recording technologies in the late nineteenth century: how is scholarship meant to deal with the absence of the very object that it sets out to study? There is no straightforward answer to this question. Surely, this dilemma is the reason that studies on sound cultures from before the mid-nineteenth century are less abundant than those about contemporary sound cultures. To admit that any approach to the study of nineteenth-century sound cultures is mediated by the printed word or by visual representation is surely wiser and more productive than trying to resist, circumvent or dissimulate that mediation. It may be objected that, should recordings exist, they would not fully solve the problem of mediation, as they are in themselves a representation of sound. But the study of non-recorded sound has the added challenge and interest that it turns the scholar's attention towards the only media in which the experiencing of sound is conveyed, requiring, for that reason, a fully interdisciplinary approach.

3 The possible combinations of disciplines from which such a study can be undertaken are manifold, and City of Noise draws on methods from literary studies, cultural studies, visual studies, cultural and social history, historical anthropology, and historical musicology, among others. Boutin's background in nineteenth-century French literature, however, gives her analysis of some of the sources an angle that is not only attractive to those of us trained in a different field, but that is necessary to understand the complex subjectivity of some of the key authorial figures involved in the transmission of knowledge and experience about sound, especially the flâneur. The sources analysed by Boutin, although they cover a wide range of formats and genres, are mainly literary works of different kinds, including poems, the Cris de Paris, and literary guidebooks. Literature, in addition to being a unique source to study emotions such as the anger provoked by the rise of uncontrolled noise in the city, is also a valuable source to explore "the creative role of sound and its potential to generate ideas about the self, the city and art" (p. 74). Literary analysis of discourse is a powerful means to account for the elusiveness of noise and sound, and to examine the contingency of these categories, and the ways in which their use is linked to the exercise of power.

Even though social history and historical anthropology are not the book's main areas, City of Noise aims in part to account for the ways in which sound control in nineteenthcentury Paris served as a tool to segregate and control the population, helped to redefine notions of citizenship, and changed perceptions of sound, noise, and their effects. The sources analysed reveal that, through their reactions to sound and noise, journalists, poets and visual artists gave expression to individual and collective desires to create, move, reinforce, or blur the boundaries between population groups, and thus to filter in and out of Parisian society the individuals who inhabited its margins. Literary and visual reactions to sound and noise helped to redefine notions of vagrancy, mendicancy, and foreignness, and mobilised public opinion in different directions, shaping divergent attitudes either against or in favour of the social groups that did not fit into the dominant socioeconomic order. These groups include glaziers, clothes sellers, street criers, peddlers, and organ grinders - who challenged the distinction between music-making and vagrancy or mendicancy. The book thus identifies and brings into question a parallel, established at the time, between, on the one hand, dissonance - conceived as an aesthetic category that is present in literature and the 
arts - and, on the other, noise and social marginality (p. 104). In addition, it shows the ways in which sound practice was a means through which peddlers, organ grinders and other street dwellers used sound and music to negotiate their weak and unstable place in Paris' modernising economy and shifting sonic ecosystem.

City of Noise also explores the ways in which physical changes made to the city's space, most especially the baron Hausmann's plan, had a deep effect in the city's sonic landscape, and changed citizens' attitudes towards noise. These transformations not only demanded that city dwellers adapt to the new sonority, but they triggered mechanisms of social control that were aimed at refining and, thus, making more effective, the strategies of social segregation through which Hausmann's plan was conceived. Urban transformation thus changed perceptions of what sounds were and were not appropriate in certain spaces and neighbourhoods, according to a middleclass ideology of comfort. By raising the standards of comfort, Hausmann's plan increased the likelihood that residents and writers published angry responses to the disruptive quality of the cries of peddlers and the music of organ grinders, and that the standards of social justice would drop in consequence. Boutin's analysis of the effects brought about by physical changes to the city's layout shows the ways in which the materiality of sound triggered responses that, however primary, were nevertheless contextual and contingent, and worked together with discourse to produce meaning and reconfigure space.

6 Time is explored in the book as a vector that changes societal priorities and that, in so doing, gains the capacity to smooth out or harmonise the social dissonance provoked by noise. The passage of time triggers feelings of nostalgia that erode the impression of danger once caused by "vagrants," peddlers, street criers and organ grinders. It is a good sign of the book's refinement that analysis of memory and nostalgia is less informed by Pierre Nora's influential but widely used lieux de mémoire than by conceptions of memory as selective amnesia (p. 77), that is, as a complex and dynamic process of forgetting and remembrance that repurposes constructions of the past in order to address present concerns. Through the effect of selective amnesia, journalists and writers "fetishised" the once threatening or uncomfortable street criers, vagrants and organ grinders. These street dwellers thus became objects of desire, fictionalised remnants of a past that was sometimes more imagined than real. Nostalgia turned into heroes the "countercultural figures" that "rise up against the tide of modern (capitalist) progress" (p. 136) - if only those of figures that were already vanishing from the public space. In that way, memory creates the illusion that social gaps are being bridged. In addition, nostalgia provided the repertoire of tropes through which coeval social critics addressed and articulated their fears that the sounds of an era might disappear forever.

7 Even though sound's mediation in social conflict is given ample consideration in City of Noise, Boutin's analysis places greater emphasis on sensitivities that - in her own words - "orchestrate" the cacophony of the city and "harmonise" street noise. This choice certainly casts a different gaze upon historical urban soundscapes than does the concentration on sources such as police records, legislation on noise and traffic, and municipal files, in which the links between street criers and social conflict are more prominent. The need to rely on multiple disciplines to study sound opens up the choice of sources to a wider range of criteria. Decisions on what sources to include or exclude, and which ones to focus more attention on carry deep consequences with them. There 
is a risk that the focus on literature and, in particular, on the figure of the flaneur, could leave out relevant realities and sensitivities that could help to put the flaneur's particular, aestheticising engagement with the city's sounds - his attempt to harmonise cacophony - in a broader perspective. From that perspective, the less elegant and more primary reactions of angry residents; the expressions of fear of class miscegenation; the measures taken to appease those fears; and the strategies of noise offenders to evade legal control and persecution - all of which are nevertheless considered by Boutin - gain more prominence.

There is, however, evidence in the book of awareness of the potential limitations of the use of literature to study social attitudes towards sound: "poets reconstruct for readers and listeners today a mediated experience" (p. 136). Boutin does not shy away from the inevitable tensions between text and context arising from the analysis of literary, journalistic or visual discourse. For that reason, she considers legislation (p. 31; p. 71), as well as insights into political and social history, as relevant factors in the analysis of meaning. At the same time, City of Noise acknowledges that the social commentators it deals with "came from non-working class backgrounds" (p.136). More important perhaps than the question of class is the value and utility attributed to writing and the purpose and motivations for leaving testimony of one's thoughts: "Any historical investigation into the sounds of the past has to work around the limited availability of firsthand accounts of sounds by people who did not think themselves significant enough to record and document" (p. 136). Class may be the most determining factor, though not the only one, in shaping attitudes towards sound and noise. To admit, in such an eloquent way, that there is more darkness surrounding the available sources than there is light in the existing ones, and to understand where the light is coming from, raises important questions and challenges for future research on urban historical soundscapes. For this reason, and thanks to the richly interdisciplinary methods through which this book challenges established views that nineteenth-century cultures were eminently visual, City of Noise will appeal to readers who are interested in exploring historical urban soundscapes from a wide range of fields and perspectives.

\section{NOTES}

1. PICKER John, Victorian Soundscapes, Oxford/New York, Oxford University Press, 2003; BIJSTERVELD Karin, Mechanical Sound: Technology, Culture and Public Problems of Noise in the Twentieth Century, Cambridge (MA),The MIT Press, 2008; HENDY David, Noise: A Human History of Sound and Listening, London, Profile Books, 2013; BIDDLE Ian, GIBSON Kirsten (eds.), Cultural Histories of Noise, Sound and Listening in Europe, 1300-1918, London/New York, Routledge, 2016. 


\section{AUTHORS}

\section{SAMUEL LLANO}

Samuel Llano is a Senior Lecturer in the Department of Modern Languages at the University of Manchester. He specialises in the study of transnational musical exchanges, urban soundscapes in history and, more recently, the music of Spanish colonialism in Morocco. His publications include Discordant Notes: Marginality and Social Control in Madrid, 1850-1930 (OUP, 2018) and Whose Spain?: Negotiating "Spanish Music" in Paris, 1908-1929 (OUP, 2012), winner of the Robert M. Stevenson Award of the American Musicological Society. He is currently working on a book project titled The Empire of the Ear: Music, Ethnography and the Sonic Architecture of Spanish Morocco, 1912-1956. 